УДК 629.715.33/617.62

Бъчков А. С. ${ }^{1}$, Нечипоренко О. Ю. ${ }^{2}$

${ }^{1}$ Государственный научно-исследовательский экспертно-криминалистический центр МВД Украины. Украина, г. Киев

${ }^{2}$ Государственное предприятие «АНТОНОВ». Украина. г. Киев

\title{
КРИТЕРИИ ЭФФЕКТИВНОСТИ ЗАМЕНЫ МАТЕРИАЛОВ ТРИБОТЕХНИЧЕСКОГО НАЗНАЧЕНИЯ ДЛЯ УЗЛОВ ТРЕНИЯ САМОЛЕТОВ СоОбЩеНИе 1. ОБЩАЯ ХАРАКТЕРИСТИКА МАТЕРИАЛОВ ТРИБОТЕХНИЧЕСКОГО НАЗНАЧЕНИЯ. АНТИФРИКЦИОННЫЕ МАТЕРИАЛЫ
}

Проведен анализ общих характеристик материалов триботехничского назначения. Синтезирована классификационная схема основных видов составов антифрикционных материалов. Разработана блоксхема формирования основных эксплуатационных характеристик антифрикционных материалов.

Классификационные составляющие әксплуатационных характеристик согласованы с относительными критериями әффективности антифрикционных материалов, иисленное определение которых реализовано в рамках предложенного концептуального подхода к критериальной оценке возможностей повышения әксплуатационных характеристик деталей авиаконструкций и метода последовательного расширения их полноты, предопределенного сформулированными целями замещения базовых антифрикционных материалов.. [dx.doi.org/10.29010/082.10]

Ключевые слова: антифрикционные материаль; классификация основных эксплуатационных характеристик; блок-схема формирования свойств; критерии эффективности замень материалов пар трения.

\section{Введение}

Одной из причин выхода из строя деталей и агрегатов является износ. Около 75 \% случаев выхода из строя узлов обусловлено износом именно пар трения. Если учесть, что, например, система управления самолетом, шасси, гидросистема и так далее - это системы, работающие вследствие перемещения их элементов, то становится понятным важность обеспечения их надежного функционирования [1-3].

Повышенный износ деталей в узле трения в одних случаях нарушает герметичность рабочего пространства, в других - нормальный режим смазки, в третьих - приводит к потере кинематической точности механизма, что ухудшает управление летательным аппаратом и снижает безопасность полета. Износ и повреждение поверхностей снижают сопротивление усталости деталей и могут быть причиной их разрушения даже при незначительных концентраторах напряжений и слишком низких номинальных нагрузках. Повышенный износ нарушает нормальное взаимодействие деталей в узлах, может вызвать значительные дополнительные нагрузки, удары в соединениях и вибрации, стать причиной внезапных разрушений. Заедание и заклинивание деталей может привести к аварийной ситуации. В этой связи материалы для работы в условиях трения относятся к важнейшим не только в самолето- и ракетостроении, но и вообще в машиностроении [1-3].

Условия работы узлов трения отличаются огромным разнообразием по скоростям скольжения, нагрузкам, составу окружающей среды и другим параметрам. Разнообразны и требования к свойствам материалов, из которых изготовлены детали триботехнического ${ }^{1}$ назначения - низкие и высокие значения коэффициента трения, допусти-

\footnotetext{
${ }^{1}$ Трибология (трибоника) - наука о трении, износе, смазке и взаимодействии контактирующих поверхностей при их взаимном перемещении. Термин введен в 1961 году в докладе ряда организаций в Британском департаменте образования и науки [4].

Триботехника - прикладной раздел трибологии, который охватывает конечную стадию процесса создания трибосопряжения (узлов, деталей и элементов пар трения) с учетом достижений трибоанализа, трибоматериаловедения и триботехнологии [4].

Триботехническое материаловедение - раздел трибологии, изучающий поведение материалов при трении (изменение структурно-фазовых особенностей поверхностных слоев трения металлов, сплавов, полимеров и других под воздействием силы трения, скорости, температуры трения, окружающей среды и других производных от них факторов) с учетом закономерностей трения и изнашивания. Триботехническое материаловедение разрабатывает принципы создания триботехнических материалов с высокой степенью надежности в эксплуатации [4].
} 
мые значения темпа износа, высокая коррозионная стойкость, достаточная жаропрочность и так далее. Причем в большинстве случаев требуется такой комплекс свойств, который не присущ какому-либо металлу или неметаллу в отдельности. Эта проблема была решена за счет создания композиционных материалов, у которых отдельные фазы выполняют заданные специфические функции. При этом только универсальность методов порошковой металлургии позволяет создавать сложные композиты с совокупностью свойств, необходимых для конкретных условий работы узла трения [6].

Материалы триботехнического назначения условно разделяют на антифрикционные и фрикционные, задача которых состоит в превращении механической энергии в тепловую, однако в первом случае это превращение должно быть минимальным, а во втором - максимальным [2].

Антифрикционные и фрикционные материалы представляют собой материалы одного класса, предназначенные для работы в условиях трения. Четкую границу между ними, исходя из значений их коэффициентов трения, установить невозможно, так как диапазоны таких значений для них часто перекрываются. Несовершенство такого признака деления усугубляется еще и тем, что значения коэффициента трения относятся всегда к двум материалам, составляющим пару трения [5, 7].

Более определенно классифицировать материалы трения можно по их назначению: материалы, используемые в тормозных и передаточных устройствах, предохранительных муфтах, относятся к фрикционным; материалы, используемые в подшипниках, втулках, в которых желателен минимум затрат работы на трение, - к антифрикционным. Эта классификация сохраняется в связи с ее практическим удобством [7-8].

С целью последующего анализа критериев эффективности антифрикционных материалов рассмотрим их общую характеристику.

Работы по созданию и промышленному использованию порошковых антифрикционных материалов для деталей узлов трения начались в 30-х годах прошлого века. Сначала порошковые антифрикционные материалы рассматривались лишь в качестве заменителей таких традиционных подшипниковых материалов как баббиты ${ }^{2}$ и бронзы. Однако быстрое развитие машиностроения и транспорта выдвинуло задачу создания новых антифрикционных материалов для все более сложных условий эксплуатации. Так, важнейшей проблемой авиации и автомобилестроения является создание антифрик- ционных материалов, способных работать без смазки, так как отказ от нее существенно упрощает конструкцию машин, облегчает их обслуживание и повышает надежность работы. Для химической, атомной и других отраслей промышленности необходимы антифрикционные материалы, способные работать в таких агрессивных средах как кислоты, щелочи, газы. Для ракетной и криогенной техники требуются антифрикционные материалы, способные работать в условиях глубокого вакуума, а также при температурах, близких к абсолютному нулю [9].

Основным требованием ко всем антифрикционным материалам является наличие минимального коэффициента трения и высокая износостойкость. Эти свойства определяют минимальные потери энергии в узлах трения и максимальный срок их службы. Наряду с этим к каждому материалу для конкретных условий его эксплуатации предъявляются дополнительные требования: жаростойкость для работы при повышенных температурах, высокая коррозионная стойкость при работе в агрессивных средах и так далее [9].

Первыми порошковыми антифрикционными материалами были пористое железо, пористый железографит, пористая бронза и бронзографит. Эти материалы и в настоящее время успешно конкурируют с литыми антифрикционными материалами типа бронз и баббитов [9].

В современном машиностроении применяется более десяти различных групп антифрикционных материалов, в которых насчитывается более 100 марок литых металлических сплавов, предназначенных для изготовления подшипников скольжения. Однако ни один из них не отвечает так полно предъявляемым к антифрикционным материалам требованиям, как порошковые пористые подшипниковые материалы. Коэффициент трения порошковых подшипников ниже, чем у некоторых баббитовых сплавов, а износ в 7-8 раз меньше; при этом они почти не изнашивают шейки вала. Время приработки пористых подшипников примерно такое же, как и баббитового сплава. Пористые подшипники могут работать в паре с закаленными и незакаленными валами, их можно обрабатывать в размер калибровкой в пресс-формах или стандартной механической обработкой [9].

\section{Постановка и решение задачи}

Анализ сравнительно многочисленных источников информации, обобщенных в монографиях [1-3], позволил синтезировать классификационную схе-

\footnotetext{
${ }^{2}$ Баббиты - сплавы на основе олова и (или) свинца с добавками алюминия, висмута, магния, меди, мышьяка, никеля, серебра, сурьмы цинка и других [5].

${ }^{3}$ Бронзы - сплавы меди с алюминием, бериллием, железом, кремнием, марганцем, мышьяком, никелем, оловом, свинцом, сурьмой, фосфором, цинком (если последний не является основной легирующей добавкой) [5].
} 


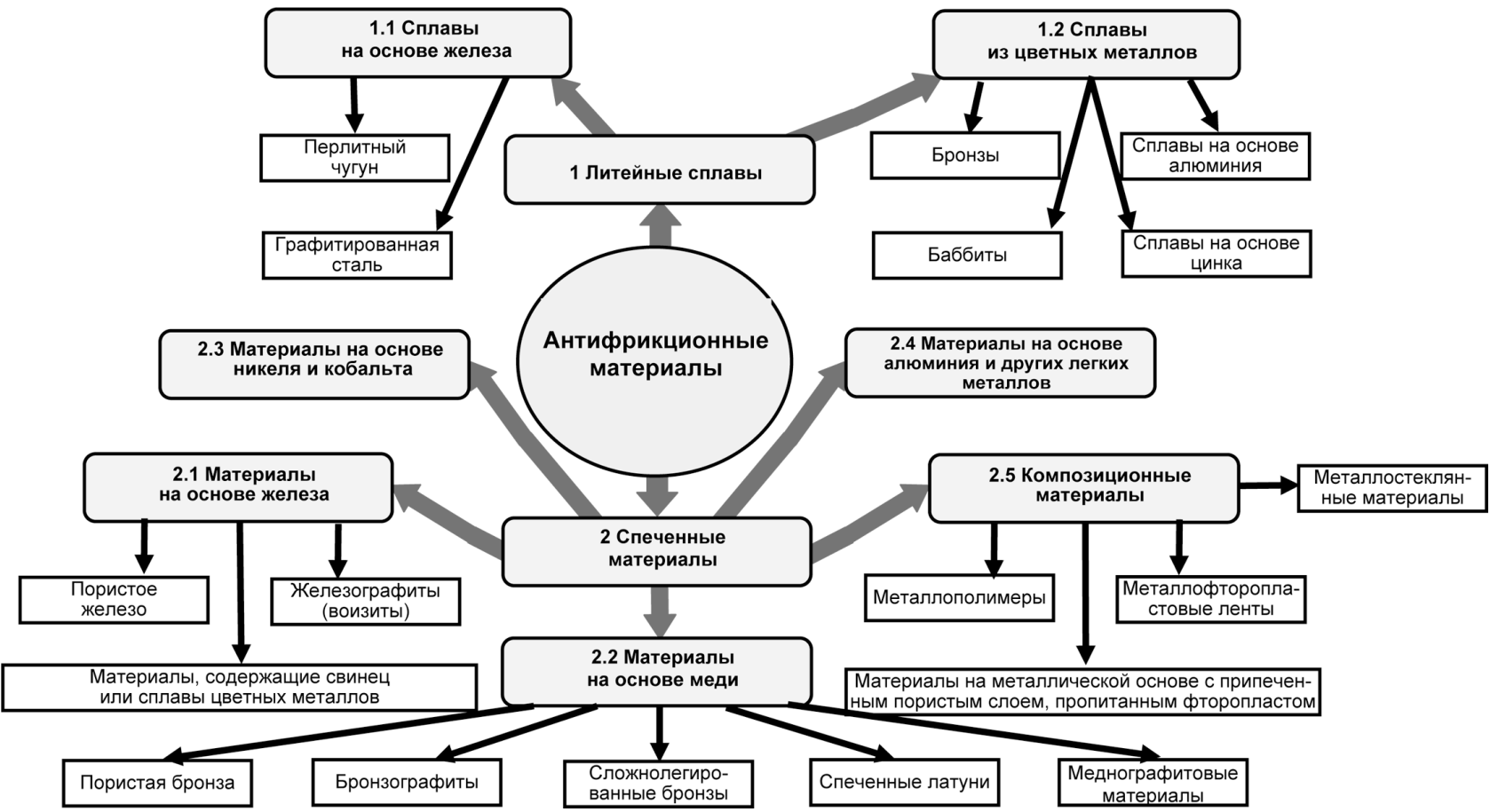

Рис. 1. Классификационная схема основных видов составов антифрикционных материалов

му основных видов составов антифрикционных материалов (рис. 1). Схема включает два основных подкласса антифрикционных материалов, составляющих класс триботехнических материалов: литейные сплавы и спеченные материалы.

Первый подкласс «Литейные сплавы» составляют две группы: сплавы на основе железа и сплавы из цветных металлов, в каждую из которых входят подгруппы материалов, отличающиеся значениями эксплуатационных характеристик, реализуемых в соответствующих условиях эксплуатации пар трения.

Второй подкласс «Спеченные материалы» включает пять групп материалов порошковой металлургии:

- материалы на основе железа;

- материалы на основе меди;

- материалы на основе никеля и кобальта;

- материалы на основе алюминия и других легких металлов;

- композиционные материалы и соответствующие им подгруппы материалов, также отличающиеся значениями эксплуатационных свойств, предопределяющих оптимальные условия эксплуатации для тех или иных пар трения.

Дальнейший анализ источников информации [1-13] и ряда других, указанных ниже, позволил синтезировать блок-схему формирования основных эксплуатационных характеристик антифрикционных материалов (рис. 2). Блок-схема включает в себя основные функциональные триботехнические (антифрикционные) свойства, составляющие три групповые характеристики, дополнительные функциональные свойства, обеспечивающие регламентированные эксплуатационные режимы работы соответствующих пар трения, в которые входят четыре групповые характеристики, а также 12 комплексных свойств, определяющих соответствующие единичные и (или) групповые свойства материалов пар трения.

Как следует из синтезированной блок-схемы (рис. 2), все эксплуатационные характеристики взаимосвязаны между собой либо непосредственно, либо опосредствованно через групповые. Так, функциональные триботехнические свойства связаны посредством низкого коэффициента трения, высокой износостойкости и свойств, обеспечивающих отсутствие заедания и схватывания с сопряженными деталями. Установлению этих связей как теоретическим (аналитическим), так и экспериментальным путем (или экспериментально-теоретическим) посвящены многочисленные фундаментальные и прикладные исследования ряда ученых и научных коллективов, интегрированные в научные основы триботехники

Таким образом, триботехнические материалы как фрикционного, так и антифрикционного подклассов всех основных составов, представленные в классификационной схеме (рис. 1), достаточно глубоко исследованы в аспекте формирования их основных эксплуатационных характеристик, систематизированных в блок-схеме (рис. 2), и эти исследования интенсивно продолжаются.

В то же время проблема системного синтеза критериев эффективности антифрикционных материа- 


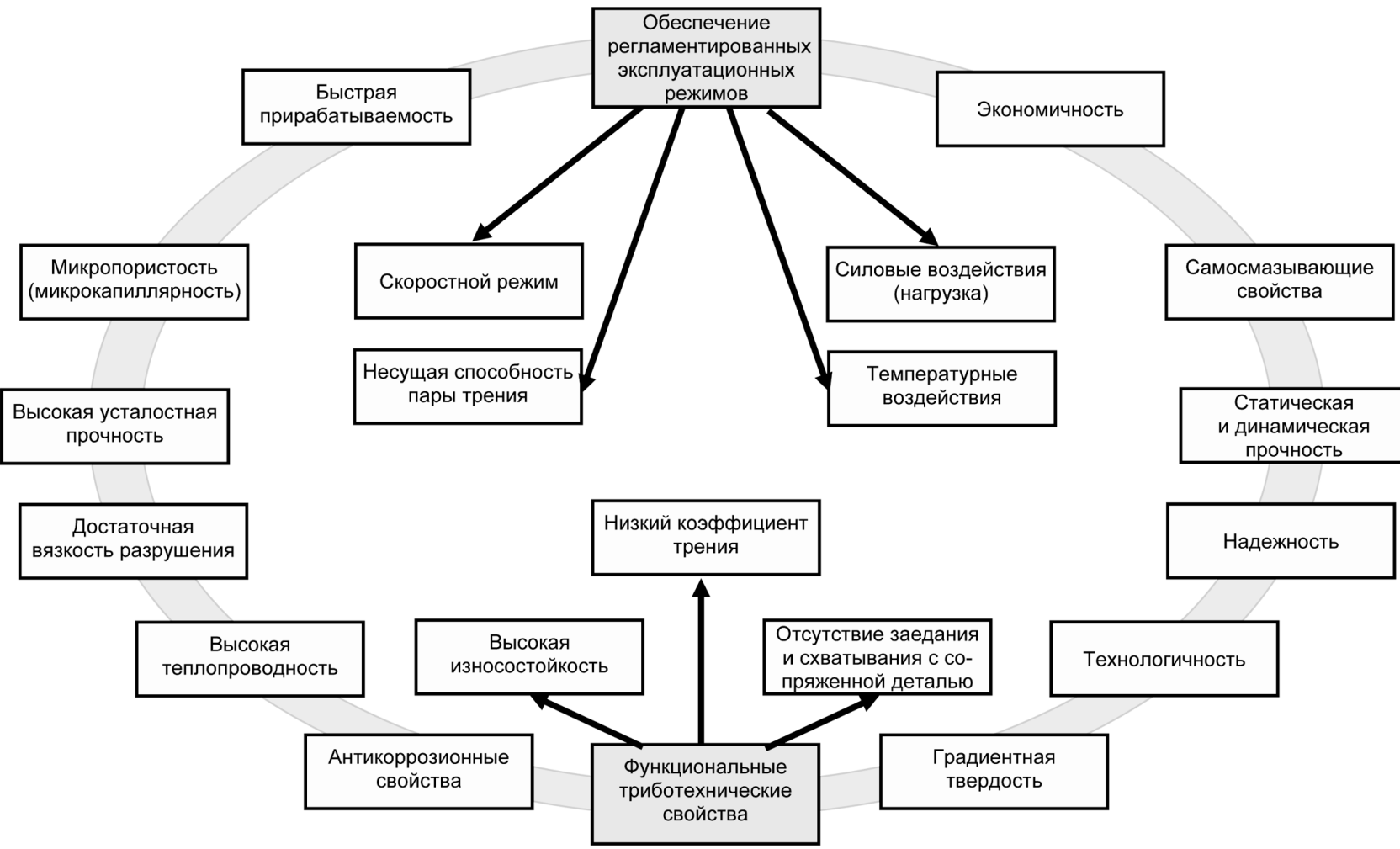

Рис. 2. Блок-схема формирования основных эксплуатационных характеристик антифрикционных материалов

лов находится на начальных стадиях ее решения [14]. Поэтому представляется оправданным первоначально дать краткий анализ состояния формирования эксплуатационных свойств основных видов их составов (рис. 1), а затем на базе этого анализа реализовать концептуальный подход к оценке эффективности замены тех или иных составов антифрикционных материалов.

В подклассе «Литейные сплавы» наиболее широко в самолетостроении применяются сплавы из цветных металлов: бронзы марок БрОФ7-0,2; БрАЖМц10-3-1,5; БрАЖН10-4-4; БрБ2; БрБ2,5; латуни марок Л-63; ЛС-59-1 (ЛЦ40С) [2, 15]. Коэффициенты сухого трения сплавов из цветных металлов $f_{\text {тр сух. }}=0,2 \ldots 0,39$, со смазкой $f_{\text {тр смаз. }}=0,12 \ldots 0,13 . \mathrm{B}$ качестве литейных антифрикционных сплавов на основе железа применяют перлитные чугуны, имеющие коэффициент сухого трения $f_{\text {тр сух. }}=0,3 \ldots 0,5$ и со смазкой $f_{\text {тр смаз. }}=0,17 \ldots 0,27$ [15], и графитизированную сталь, имеющую коэффициент трения такого же порядка, как и перлитные чугуны.

Как отмечено в [3], принято считать, что коэффициент трения антифрикционных материалов составляет 0,001...0,05 при наличии смазки и 0,004...0,5 при ее отсутствии.

Понятие «антифрикционность» включает следующий комплекс свойств:

- хорошая начальная прирабатываемость в работе, то есть время, необходимое для снижения коэффициента трения между подшипником и валом до заданной величины, должно быть минимальным;

- высокие триботехнические свойства (износостойкость, коэффициент трения);

- способность выдерживать нагрузку, скорость и температуру без разрушения и изменения формы и качества;

- способность образовывать самосмазывающиеся или легко притирающиеся продукты истирания коллоидного характера (пленку), которые могут сберечь шейку вала от износа даже при затрудненной смазке;

- меньшая твердость, чем у шейки вала, причем твердость должна снижаться как можно меньше с нагревом;

- высокая теплопроводность для хорошего отвода тепла трения;

- достаточная выносливость или сопротивление усталости;

- хорошие технологические свойства;

- микропористость или микрокапиллярность, способствующие удержанию смазки;

- хорошие антикоррозионные свойства;

- достаточные статическая и динамическая прочность при повышенных температурах [8, 12].

Антифрикционных материалов, удовлетворяющих всем этим требованиям, не существует. Каждый из материалов антифрикционен при определенных режимах трения. Об антифрикционности какого-либо материала судят по его коэффициенту 
трения с сопряженной деталью при граничной смазке или другом режиме трения при прочих равных условиях, по объему повреждений поверхностей трения, по температуре этих поверхностей и вероятности заедания или налипания материалов и так далее [8, 12].

Указанный выше комплекс свойств является существенной составляющей блок-схемы (рис. 2). Диапазоны изменения коэффициентов трения антифрикционных материалов, по-видимому, можно рассматривать как ограничивающие $f_{\text {тр смаз. }}$ $f_{\text {трсух. }}$ по максимальным значениям для литейных сплавов, а меньшие показатели относить к материалам, составляющим группы подкласса спеченных материалов классификационной схемы (рис. 1).

Для определенности в дальнейшем подходе к критериальной оценке возможностей повышения эксплуатационных характеристик деталей авиаконструкций при формировании их относительных значений в безразмерном выражении [14] в качестве базового антифрикционного материала принята бронза БрАЖМц10-3-1,54 (прессованные прутки) с коэффициентом трения со смазкой $f_{\text {тр смаз. }}=0,12$ и без смазки $f_{\text {тр сух. }}=0,2$. Химический состав бронзы БрАЖМц10-3-1,5 приведен в табл. 1, ее физико-механические свойства представлены в табл. 2.

Специфической особенностью антифрикционных материалов является взаимозависимость их триботехнических свойств как от материала контртела пары трения, так и от режима эксплуатации (рис. 2), а также их групповых свойств у всех видов составов (рис. 1). В качестве примера в табл. 3 приведены коэффициенты трения спеченных порошковых бронз при различных режимах работы, а в табл. 4 - свойства сульфидированного железа и железографита в зависимости от количества графита и типа структуры. Примеры взаимозависимости эксплуатационных характеристик можно было бы продолжить.

Приступим к реализации концептуального подхода к критериальной оценке эффективности рациональной замены различных составов антифрикционных материалов, изложенного в работе [14], применительно к деталям, изготавливаемым методами порошковой металлургии.

Таблица 1

Химический состав бронзы БрАЖМц10-3-1,5 в масс. \% [2]

\begin{tabular}{|c|c|c|c|c|c|c|c|c|c|c|c|c|}
\hline \multirow{2}{*}{$\mathbf{C u}$} & $\mathbf{A l}$ & $\mathbf{F e}$ & $\mathbf{M n}$ & $\mathbf{A s}$ & $\mathbf{S b}$ & $\mathbf{S n}$ & $\mathbf{S i}$ & $\mathbf{P b}$ & $\mathbf{P}$ & $\mathbf{Z n}$ & $\mathbf{N i}$ & $\begin{array}{c}\text { Сумма } \\
\text { примесей }\end{array}$ \\
\cline { 5 - 12 } & & & \multicolumn{8}{|c|}{ Не более } \\
\hline Основа & $\begin{array}{c}9,0 \ldots \\
11,0\end{array}$ & $\begin{array}{c}2,0 \ldots \\
4,0\end{array}$ & $\begin{array}{c}1,0 \ldots \\
2,0\end{array}$ & 0,01 & 0,002 & 0,1 & 0,1 & 0,03 & 0,01 & 0,5 & 0,5 & 0,75 \\
\hline
\end{tabular}

Таблица 2

Физико-механические характеристики бронзы БрАЖМц10-3-1,5 [2]

\begin{tabular}{|c|c|}
\hline Наименование свойства & Значение \\
\hline Предел прочности при растяжении $\sigma_{\mathrm{B}}$, МПа & 650 \\
\hline Предел усталости на базе $5 \cdot 10^{7}$ циклов $\sigma_{-1}$, МПа & 250 \\
\hline Модуль упругости $E$, ГПа & 105 \\
\hline Условный предел текучести при растяжении $\sigma_{0,2}$, МПа & 350 \\
\hline Относительное удлинение $\delta_{10}, \%$ & 10 \\
\hline Твердость по Бринеллю $H B$, МПа & 1600 \\
\hline Плотность $d$, кг $/ \mathrm{m}^{3}$ & 7500 \\
\hline Коэффициент теплопроводности $\lambda$, Вт/(м·К) & 58,6 \\
\hline Коэффициент линейного теплового расширения $\alpha, K^{-1}$ & $16 \cdot 10^{-6}$ \\
\hline Удельное электрическое сопротивление $\rho$, мкОм·м & 0,019 \\
\hline Коррозионная стойкость & $\begin{array}{c}\text { Высокая в атмосферных условиях, } \\
\text { пресной и морской воде }\end{array}$ \\
\hline Удельная тепоемкость $c$, кДж/(кг·К) & 0,377 \\
\hline
\end{tabular}

\footnotetext{
${ }^{4}$ Выбор базового материала не принципиален, но предполагает относительную близость его эксплуатационных характеристик к среднестатистическим значениям подкласса выбранного литейного материала.
} 
Коэффициент трения бронз при различных режимах работы [11]

\begin{tabular}{|c|c|c|c|}
\hline \multirow{2}{*}{ Марка бронзы } & \multicolumn{3}{|c|}{ Скорость скольжения, м/с } \\
\hline & 1 & 2 & 3 \\
\hline \multicolumn{4}{|c|}{ Нагрузка 1,8 МПа } \\
\hline БрО10 & 0,13 & 0,09 & - \\
\hline БрОЦ10-2 & 0,07 & 0,06 & 0,05 \\
\hline БрОЦ10-2 (отожженный порошок) & 0,04 & 0,04 & 0,04 \\
\hline $\begin{array}{l}\text { БрО10 (смесь порошков электролит } \\
\text { и распыленного олова) }\end{array}$ & & & \\
\hline \multicolumn{4}{|c|}{ Нагрузка 6,0 МПа* } \\
\hline БрОЦ10-2 (отожженный порошок) & 0,09 & 0,08 & 0,08 \\
\hline
\end{tabular}

* При нагрузке 6,0 МПа происходило схватывание поверхностей трения образцов из распыленных порошков и оловянистоцинковой (неотожженной) бронзы, а также из смеси порошков.

Таблица 4

Свойства сульфидированного железа и железографита в зависимости от количества графита и типа структуры [10]

\begin{tabular}{|c|c|c|c|c|c|c|c|c|c|c|c|}
\hline \multicolumn{2}{|c|}{$\begin{array}{c}\text { Исходный } \\
\text { материал, \% }\end{array}$} & \multirow{2}{*}{$\begin{array}{l}\text { Струк- } \\
\text { тура* }\end{array}$} & \multicolumn{2}{|c|}{$\begin{array}{c}\text { Спеченный } \\
\text { материал, \% }\end{array}$} & \multirow[t]{2}{*}{ П, \% } & \multirow{2}{*}{$\begin{array}{l}\text { HB, } \\
\text { МПа }\end{array}$} & \multirow{2}{*}{$\begin{array}{c}\text { Нагрузка } \\
\text { схватывания } p_{\text {схв }} \\
\text { при } v=0,45 \mathrm{M} / \mathrm{c}, \\
\text { МПа }\end{array}$} & \multicolumn{2}{|c|}{$\begin{array}{c}\text { Износ } \\
\text { при } v=0,9 \text { м } / \mathbf{c} \\
\text { и } p=4,9 \text { МПа }\end{array}$} & \multirow[t]{2}{*}{$\mathrm{f}$} & \multirow{2}{*}{$\begin{array}{c}\tau_{\text {пр }}, \\
\text { мин }\end{array}$} \\
\hline C & $\mathrm{ZnS}$ & & $\mathbf{S}$ & $\mathbf{C}_{\text {общ }}$ & & & & $\begin{array}{c}\text { ролика, } \\
\text { мг }\end{array}$ & $\begin{array}{c}\text { вкладыша, } \\
\text { мкм }\end{array}$ & & \\
\hline 0 & 4 & $\Phi$ & 1,2 & 0,5 & 16,1 & 748,5 & 2,35 & схв. & схв. & 0,01 & 10 \\
\hline 1 & 4 & ПФ & 1 & 1 & 18,1 & 466 & 6,28 & 1,3 & 4 & 0,01 & 10 \\
\hline 3 & 4 & $\Pi \Phi$ & 1,1 & 2,2 & 14,6 & 612 & 5,10 & 1,5 & 8 & 0,007 & 20 \\
\hline 5 & 4 & ПФ & 1,1 & 3,7 & 21,9 & 325 & 2,94 & 1,2 & 12 & 0,015 & 25 \\
\hline 0 & 4 & $\overline{\Pi \Pi \Phi}$ & 0,9 & 0,8 & 15,5 & 1118 & 1,57 & 1,4 & 14 & 0,02 & 40 \\
\hline 1 & 4 & $\Pi$ & 1 & 1,35 & 18,7 & 932 & 5,10 & 1,4 & 9 & 0,01 & 90 \\
\hline 3 & 4 & $\Pi$ & 1 & 2,7 & 13,5 & 1050 & 8,83 & 3,2 & 5 & 0,007 & 140 \\
\hline 5 & 4 & $\Pi$ & 1 & 4,15 & 19,0 & 833 & 2,94 & 1,8 & 6 & 0,015 & 130 \\
\hline
\end{tabular}

* Ф - феррит; П - перлит; ПФ - перлито-феррит.

Предложенная в работе [14] блок-схема критериев в значительной степени может быть сохранена и для материалов антифрикционного назначения как в плане градации критериев на единичные, групповые, комплексные и интегральный, так и в аспекте функциональной аналогии комплексных критериев. Это подтверждается их сравнением путем сопоставления входящих составляющих в блок-схему рис. 1 работы [14] с блок-схемой рис. 2, приведенной выше.

Комплексные критерии работы [14], такие как надежность, экономичность, технологичность, совпадают полностью с приведенными на рис. 2 эксплуатационными характеристиками. Ряд эксплуатационных свойств (статическая и динамическая прочность, твердость, несущая способность, износостойкость, усталостная прочность, вязкость раз- рушения) являются составляющими комплексного критерия «Предельные состояния». Эксплуатационные характеристики рис. 2 «Функциональные триботехнические свойства», «Характеристики обеспечения регламентированных эксплуатационных режимов» с входящими в них составляющими являются частными показателями комплексного критерия работы [14] «Нормированная среда эксплуатации».

В практике анализа тех или иных триботехнических материалов широко используют частный критерий несущей способности пары трения $p v \leq[p v]$, где $p-$ удельная нагрузка, а $v-$ скорость скольжения, $[p v]-$ допустимое значение несущей способности пары трения.

Комплексный критерий работы [14] «Показатели качества» отражает эксплуатационные характе- 
ристики блок-схемы рис. 2 «Самосмазывающие свойства», «Антикоррозионные свойства», «Высокая теплопроводность», «Микропористость», «Быстрая прирабатываемость». Комплексный критерий «Назначенный ресурс», как и в схеме рис. 1 работы [14], предполагает интеграцию (включение в себя) критериев «Предельные состояния», «Надежность» и «Нормированная среда эксплуатации». Критерий «Весовая отдача» рис. 1 работы [14] четко не выражен в блок-схеме рис. 2, однако при необходимости может быть учтен своими составляющими в процессе численного формирования интегрального критерия эффективности рациональной замены материалов.

Сам метод концептуального подхода к критериальной оценке эффективности [14] применительно к антифрикционным материалам полностью сохраняет силу, а именно реализуется вычислением относительного интегрального критерия.

По аналогии с [14], относительный интегральный критерий заменяющего антифрикционного материала $\bar{K}_{\text {инт }}$ определяется зависимостью

$$
\bar{K}_{\text {инт }}=\sum_{i=1}^{n} \alpha_{i} \bar{R}_{\text {комплл }}\left(\bar{K}_{i}\right)>1,
$$

где $\bar{R}_{\text {компл } i}\left(\bar{K}_{i}\right)-i$-й комплексный критерий заменяющего антифрикционного материала $R_{\text {аф }}$, отнесенный к аналогичному критерию базового материала $R_{\text {аф баз } i}$

$$
\bar{R}_{\text {компл } i}\left(\bar{K}_{i}\right)=\frac{R_{\text {аф } i}}{R_{\text {аф баз } i}},
$$

$\alpha_{i}-$ коэффициент значимости соответствующих комплексных критериев рис. 2, определяемый экспертным путем, реализуемым лицом, принимающим решение (ЛПР) [17-19].

Входящие в (1) относительные комплексные критерии $\bar{R}_{\text {компл } i}\left(\bar{K}_{i}\right)$ в качестве составляющих включают в себя соответствующие групповые

$$
\bar{K}_{\text {компл } i}=\sum_{i=1}^{m} \beta_{i} \bar{R}_{\text {гр } i},
$$

$\sum_{i=1}^{m} \beta_{i}=1, \beta_{i}-$ коэффициенты значимости соответствующих критериев $\bar{K}_{\text {гр }}$, назначаемые ЛПР на базе экспертных оценок. $\bar{K}_{\text {ед } i}$

В свою очередь $\bar{K}_{\text {гр } і}$ включают в себя единичные

$$
\bar{K}_{\mathrm{rp} i}=\sum_{i=1}^{r} \gamma_{i} \bar{R}_{\mathrm{e} \lambda i},
$$
$\sum_{i=1}^{m} \gamma_{i}=1, \gamma_{i}-$ коэффициенты значимости соответ-
В случае, если по своему характеру входящие в заменяемый материал составляющие комплексного критерия при своем снижении обеспечивают повышение эффективности (рост) комплексного критерия, то относительный комплексный критерий такой замены должен отражаться обратной по отношению к (1) зависимостью.

Так, комплексный критерий стоимости $K_{\mathrm{c}}$ предопределяет эффективность замены базового материала на другой, если сумма входящих в него групповых критериев базового материала $R_{i}$ ниже, чем ее значение у заменяемого материала, т.е. имеет место обратная (1) зависимость

$$
\bar{R}_{i}\left(K_{\mathrm{c}}\right)=\frac{R_{\text {аф баз } i}}{R_{\text {аф } i}} \geq 1 .
$$

Как показано в работе [20], вследствие отсутствия достаточного количества данных по эксплуатационным характеристикам как базового, так и заменяющего антифрикционного материала, а также практической необходимости учета чрезмерно большого их количества, представляется эффективной ограниченная полнота располагаемого объема свойств антифрикционных материалов с последующем ее расширением по мере накопления данных, а также в зависимости от целей их замены.

Анализ наиболее значимых целей замещения базовых антифрикционных материалов позволил выделить следующие:

- увеличение ресурса и надежности антифрикционных пар трения авиаконструкций путем повышения функциональных триботехнических эксплуатационных характеристик материалов;

- снижение стоимости антифрикционных материалов;

- снижение производственных затрат на изготовление антифрикционных деталей пар трения;

- импортозамещение антифрикционных материалов;

- повышение производственной безопасности жизнедеятельности, охраны труда, выполнение экологических требований к культуре производства.

В заключение в табл. 5-8 приведены некоторые факторы, влияющие на свойства антифрикционных материалов.

\section{Выводы}

1. Проведен анализ общих характеристик материалов триботехнического назначения.

2. Синтезирована классификационная схема основных видов составов антифрикционных материалов, включающая литейные сплавы и спеченные материалы, а также группы и подгруппы этих 
Влияние содержания графита на свойства антифрикционных спеченных материалов на основе железа [10]

\begin{tabular}{|c|c|c|c|c|c|c|c|c|c|}
\hline $\begin{array}{c}\text { Содержание } \\
\text { графита, \% }\end{array}$ & $\begin{array}{l}\Pi \text {, } \\
\%\end{array}$ & HB, МПа & $\begin{array}{c}\sigma_{\mathrm{B}}, \\
\text { МПа }\end{array}$ & $\sigma_{\text {изг }}$, МПа & $\sigma_{\mathrm{c} *}, \mathrm{M \Pi а}$ & $\begin{array}{c}a_{\mathrm{k}}, \\
\text { Дж/cm }\end{array}$ & $\begin{array}{l}p_{\text {max }}, \\
\text { MIIa }\end{array}$ & $\begin{array}{c}v, \\
\mathbf{M} / \mathbf{c}\end{array}$ & $\begin{array}{c}p v, \\
\mathbf{M} \cdot \mathbf{a} \cdot \mathbf{c}\end{array}$ \\
\hline $0,5 \ldots 0,8$ & $6 \ldots 26$ & $637 \ldots 785$ & $95 \ldots 460$ & - & - & $19 \ldots 49$ & - & 2 & 7,85 \\
\hline $0,8 \ldots 1,5$ & $14 \ldots 27$ & $590 \ldots 1820$ & $180 \ldots 590$ & 177 & $490 \ldots 785$ & $9,8 \ldots 29,4$ & $3,9 \ldots 4,9$ & $2 \ldots 3$ & 7,85 \\
\hline $1,5 \ldots 2,3$ & $15 \ldots 35$ & $540 \ldots 1275$ & $78 \ldots 590$ & $98 \ldots 590$ & $390 \ldots 785$ & $0,6 \ldots 5,9$ & 3,93 & 4 & $6,8 \ldots 29,5$ \\
\hline $2,3 \ldots 3,0$ & $17 \ldots 35$ & $295 \ldots 1420$ & $69 \ldots 275$ & $216 \ldots 440$ & $490 \ldots 687$ & $2,0 \ldots 9,8$ & $2,9 \ldots 9,8$ & 4 & 2,45 \\
\hline 5 & $16 \ldots 19$ & $785 \ldots 960$ & $226 \ldots 255$ & $356 \ldots 456$ & - & $6,9 \ldots 8,9$ & 14,7 & 4 & 1,96 \\
\hline 7 & $18 \ldots 25$ & $245 \ldots 736$ & $147 \ldots 186$ & $196 \ldots 319$ & $490 \ldots 590$ & $1,47 \ldots 5,9$ & 6,87 & 4 & 1,96 \\
\hline 10 & $21 \ldots 23$ & $412 \ldots 569$ & $84,3 \ldots 147$ & $142 \ldots 231$ & - & 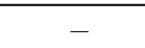 & - & - & - \\
\hline
\end{tabular}

Таблица 6

Влияние содержания меди на свойства антифрикционных спеченных материалов на основе железа [10]

\begin{tabular}{|c|c|c|c|c|c|c|c|c|}
\hline $\begin{array}{c}\text { Содержание } \\
\text { меди, \% }\end{array}$ & $\begin{array}{l}\text { I, } \\
\%\end{array}$ & $\begin{array}{c}\text { HB, } \\
\text { МПа }\end{array}$ & $\begin{array}{c}\sigma_{\mathrm{B}}, \\
\text { МПа }\end{array}$ & $\begin{array}{c}\sigma_{\mathrm{c} \text { }}, \\
\text { MПа }\end{array}$ & $\begin{array}{l}\delta, \\
\%\end{array}$ & $\begin{array}{l}p_{\max }, \\
\text { MПа }\end{array}$ & $\begin{array}{c}v, \\
\mathbf{M} / \mathbf{c}\end{array}$ & $\begin{array}{c}p v, \\
\text { МПа·М/c }\end{array}$ \\
\hline 2 & $20 \ldots 30$ & $589 \ldots 883$ & $216 \ldots 265$ & - & 6 & 93 & - & 1,6 \\
\hline $2,5 \ldots 3$ & $13 \ldots 18$ & $490 \ldots 1079$ & $186 \ldots 314$ & - & $2 \ldots 5$ & - & - & - \\
\hline 5 & $16 \ldots 32$ & $245 \ldots 1275$ & $74 \ldots 383$ & 863 & $0,55 \ldots 3$ & 93 & $0,5 \ldots 3$ & - \\
\hline $7 \ldots 7,5$ & $16 \ldots 22$ & $579 \ldots 1256$ & $206 \ldots 442$ & 1118 & $0,08 \ldots 0,45$ & - & - & - \\
\hline 10 & 25 & $589 \ldots 1275$ & $126 \ldots 383$ & 863 & 2,6 & 123 & - & 2 \\
\hline 15 & $13 \ldots 20$ & - & 59 & - & - & 59 & - & 1,6 \\
\hline 20 & 20 & $805 \ldots 834$ & $285 \ldots 314$ & - & $0,9 \ldots 1$ & - & - & - \\
\hline $7 \ldots 22$ & 18 & - & 235 & - & 0,5 & - & - & - \\
\hline $18 \ldots 22$ & 18 & - & 318 & - & 0,5 & - & - & - \\
\hline 25 & 25 & 442 & 186 & 1226 & - & 284 & - & - \\
\hline 40 & 16 & - & 98 & - & 0,5 & - & - & 1,6 \\
\hline
\end{tabular}

Таблица 7

Эксплуатационные характеристики СВС-материалов на основе меди [21]

\begin{tabular}{|c|c|c|c|c|c|}
\hline $\begin{array}{c}\text { Химический состав материала, } \\
\mathbf{\%}\end{array}$ & $\boldsymbol{\sigma}_{\text {сж}}$, МПа & $\begin{array}{c}\text { Усадка при } \\
\text { сжатии, \% }\end{array}$ & $\boldsymbol{l}$, мкм/км & $\boldsymbol{f}$ & $\begin{array}{c}\boldsymbol{H B}, \\
\text { МПа }\end{array}$ \\
\hline \multicolumn{7}{|c|}{ Сплавы на основе меди (бронзы) } \\
\hline $8 \mathrm{Al}-\mathrm{Cu}$ & 88010 & 40 & 0,025 & 0,052 & 70030 \\
\hline $10 \mathrm{Al}-\mathrm{Cu}$ & 87030 & 32 & 0,030 & 0,050 & 86030 \\
\hline $10 \mathrm{Al}-8 \mathrm{Ni}-\mathrm{Cu}$ & 97020 & 37 & 0,045 & 0,040 & 72020 \\
\hline $10 \mathrm{Al}-8 \mathrm{Ni}-\mathrm{Cu}$ & 109010 & 28 & 0,040 & 0,050 & 78030 \\
\hline $10 \mathrm{Al}-4 \mathrm{Fe}-4 \mathrm{Ni}-\mathrm{Cu}$ & 86030 & 18 & 0,030 & 0,050 & 65020 \\
\hline $10 \mathrm{Al}-10 \mathrm{Sn}-30 \mathrm{~Pb}-\mathrm{Cu}$ & 68020 & 30 & 0,060 & 0,030 & 44020 \\
\hline $9 \mathrm{Al}-3 \mathrm{Ti}-3 \mathrm{Ni}-3 \mathrm{Fe}-\mathrm{Cu}$ & 89020 & 24 & 0,040 & 0,056 & 68023 \\
\hline \multicolumn{7}{|c|}{ Композиционные материалы } \\
\hline $30 \mathrm{Al} \mathrm{O}_{3}-(18 \mathrm{Ti}-\mathrm{Cu})$ & 32020 & 10 & 0,016 & 0,080 & - \\
\hline $30 \mathrm{TiC}-(9 \mathrm{Al}-3 \mathrm{Ti}-3 \mathrm{Ni}-\mathrm{Cu})$ & 37520 & 12 & 0,020 & 0,072 & - \\
\hline $20 \mathrm{TiC}-(10 \mathrm{Al}-8 \mathrm{Ni}-\mathrm{Cu})$ & 45020 & 14 & 0,012 & 0,060 & - \\
\hline
\end{tabular}


Таблица 8

Физико-химические и триботехнические характеристики меди и порошковых композиционных материалов на ее основе [22]

\begin{tabular}{|c|c|c|c|c|c|c|c|c|c|c|}
\hline \multirow{2}{*}{ Материал } & \multirow{2}{*}{ 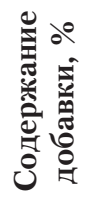 } & \multirow{2}{*}{ П, \% } & \multirow{2}{*}{$\begin{array}{l}\text { HB, } \\
\text { МПа }\end{array}$} & \multirow{2}{*}{ 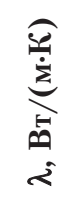 } & \multicolumn{2}{|c|}{$f$ при $v$, м/с } & \multicolumn{2}{|c|}{$\begin{array}{l}l, \text { мкм/км } \\
\text { при } v, \text { м/с }\end{array}$} & \multicolumn{2}{|c|}{$T,{ }^{\circ} \mathrm{C}$ при $v, \mathrm{~m} / \mathrm{c}$} \\
\hline & & & & & 11 & 22 & 11 & 22 & 11 & 22 \\
\hline Медь & - & 9 & 560 & 361 & 0,36 & 0,30 & 0,8 & 0,1 & 160 & 145 \\
\hline \multirow{6}{*}{ Медь с муллитом } & 0,5 & 10,4 & 630 & - & 0,37 & - & - & - & 150 & - \\
\hline & 1,0 & 10,7 & 560 & - & 0,37 & - & 0,2 & - & 170 & - \\
\hline & 2,0 & 8,9 & 500 & - & 0,31 & - & - & - & 175 & - \\
\hline & 4,0 & 9,5 & 500 & - & 0,29 & 0,29 & 0,4 & 0,2 & 160 & - \\
\hline & 6,0 & 7,4 & 763 & - & 0,32 & 0,28 & - & 0,5 & 130 & 160 \\
\hline & 10,0 & 7,8 & 849 & - & 0,36 & 0,27 & 0,3 & 0,5 & 175 & 160 \\
\hline \multirow{6}{*}{ Медь с ситаллом } & 0,5 & 7,8 & 568 & - & 0,31 & 0,23 & 0,3 & 0,9 & 155 & 180 \\
\hline & 1,0 & 7,5 & 568 & - & 0,30 & 0,27 & - & 1,6 & 175 & 240 \\
\hline & 2,0 & 8,0 & 518 & - & 0,39 & 0,26 & 1,6 & 0,7 & 150 & 130 \\
\hline & 4,0 & 7,1 & 570 & - & 0,40 & 0,38 & 0,2 & 0,7 & 160 & 270 \\
\hline & 6,0 & 8,7 & 512 & - & 0,38 & 0,26 & 0,5 & 0,9 & 190 & 180 \\
\hline & 10,0 & 8,8 & 564 & - & 0,35 & 0,42 & 0,5 & 0,5 & 115 & 225 \\
\hline \multirow{5}{*}{ Медь с серой } & 0,15 & 10,0 & 568 & 355 & 0,41 & - & - & - & 200 & - \\
\hline & 0,25 & 10,5 & 543 & 335 & 0,35 & 0,26 & - & 0,4 & 180 & 230 \\
\hline & 0,50 & 9,7 & 555 & 347 & 0,35 & 0,24 & 0,5 & 0,7 & 200 & 200 \\
\hline & 0,75 & 10,2 & 595 & 327 & 0,37 & 0,24 & - & 0,6 & 190 & 200 \\
\hline & 1,0 & 10,3 & 496 & 323 & 0,39 & 0,24 & 0,8 & 0,2 & 190 & 220 \\
\hline \multirow{2}{*}{$\begin{array}{c}\text { Медь с } \\
\text { дисульфидом } \\
\text { молибдена }\end{array}$} & 1,25 & 10,0 & 624 & 320 & 0,44 & 0,27 & - & 0,9 & 180 & 220 \\
\hline & 2,5 & 9,9 & 639 & 320 & 0,46 & 0,24 & 2,2 & 0,8 & 230 & 240 \\
\hline \multirow{3}{*}{ Медь с графитом } & 3 & 4,5 & 490 & - & 0,55 & 0,60 & 55,3 & КИ* & 220 & - \\
\hline & 7 & 6,5 & 260 & - & 0,30 & 0,20 & 11,3 & КИ* & 160 & - \\
\hline & 10 & 7,6 & 209 & 320 & 0,13 & 0,10 & 3,8 & 4,1 & 70 & 70 \\
\hline \multirow{5}{*}{$\begin{array}{c}\text { Медь с графитом } \\
(10 \%) \text { и серой }\end{array}$} & 0,15 & 10,5 & 230 & 320 & - & - & КИ* & - & - & - \\
\hline & 0,25 & 9,3 & 296 & 321 & 0,10 & 0,09 & 1,4 & 1,9 & 70 & 70 \\
\hline & 0,50 & 8,3 & 310 & 335 & 0,13 & 0,10 & 1,8 & 3,5 & 70 & 60 \\
\hline & 0,75 & 9,6 & 310 & 327 & 0,13 & 0,10 & 1,8 & 4,3 & 60 & 80 \\
\hline & 1,0 & 9,8 & 300 & 320 & 0,13 & 0,10 & 0,8 & 3,5 & 60 & 85 \\
\hline \multirow{2}{*}{$\begin{array}{c}\text { Медь с графитом } \\
(10 \%) \text { и } \\
\text { дисульфидом } \\
\text { молибдена }\end{array}$} & 1,25 & 9,8 & 240 & 320 & 0,15 & 0,12 & 2,4 & 4,6 & 60 & 70 \\
\hline & 2,50 & 9,0 & 250 & 304 & 0,12 & 0,09 & 0,9 & 4,3 & 65 & 75 \\
\hline
\end{tabular}

* КИ - катастрофический износ 
подклассов, отличающиеся значениями эксплуатационных характеристик, реализуемых в соответствующих условиях эксплуатации пар трения.

3. Разработана блок-схема формирования основных эксплуатационных характеристик антифрикционных материалов, включающая основные и дополнительные функциональные антифрикционные свойства, обеспечивающие регламентированные режимы работы соответствующих пар трения, а также 12 взаимосвязанных комплексных свойств, формирующих те или иные групповые и единичные характеристики.

4. Соответствующие классификационные составляющие эксплуатационных характеристик согласованы с относительными критериями эффективности антифрикционных триботехнических материалов пар трения, численное определение которых реализовано в рамках предложенного ранее [14] концептуального подхода к критериальной оценке возможностей повышения эксплуатационных характеристик деталей авиаконструкций и метода последовательного расширения их полноты [20], предопределенного сформулированными целями замещения базовых антифрикционных материалов.

5. Приведены некоторые определяющие факторы, влияющие на эксплуатационные характеристики антифрикционных материалов пар трения.

\section{Литература}

[1] Специальные технологии и материалы порошковой металлургии [Текст] / Д.С. Кива, С.А. Бычков, О.Ю. Нечипоренко, И.Г. Лавренко. - К.: КВИЦ, 2014. -664 c.

[2] Конструкционные материалы в самолетостроении [Текст] / А.Г. Моляр, А.А. Коцюба, А.С. Бычков, О.Ю. Нечипоренко. - К.: КВИЦ, 2015. - 400 c.

[3] Порошковые материалы для авиационной и ракетно-космической техники [Текст] / А.А. Коцюба, А.С. Бычков, О.Ю. Нечипоренко, И.Г. Лавренко. К.: КВИЦ, 2016. - 304 с.

[4] Словарь-справочник по трению, износу и смазке [Текст] / В.Л. Зозуля, Е.Л. Шведков, Д.Я. Ровинский, Э.Д. Браун. - К.: Наукова думка, 1990. - 264 с.

[5] Шведков, Е.Л. Словарь-справочник по порошковой металлургии [Текст] / Е.Л. Шведков, Э.Т. Денисенко, И.И. Ковенский. - К.: Наукова думка, 1982. $272 \mathrm{c.}$

[6] Митин, Б.С. Порошковая металлургия аморфных и микрокристаллических материалов [Текст] / Б.С. Митин, В.А. Васильев. - М.: Металлургия, 1992. $-128 \mathrm{c}$.

[7] Федорченко, И.М. Современные фрикционные материалы [Текст] / И.М. Федорченко, В.М. Крячек, В.М. Панаиоти. - К.: Наукова думка, 1975. - 336 с.

[8] Порошковая металлургия и напыление покрытий: Учебник для вузов [Текст] / В.Н. Анциферов,
Г.В. Бобров, Л.К. Дружинин и др. - Под ред. Б.С. Митина. - М.: Металлургия, 1987. - 792 с.

[9] Цукерман, В.А. Порошковые и композиционные материалы [Текст] / В.А. Цукерман. - М.: Наука, 1976. - $128 \mathrm{c}$.

[10] Федорченко, И.М. Спеченные материалы для узлов трения [Текст] / И.М. Федорченко // Актуальные проблемы порошковой металлургии. - Под ред. О.В. Романа, В.С. Аруначалма. - М.: Металлургия, 1990. - С. $12-53$.

[11] Применение порошковых бронз для антифрикционных материалов [Текст] / О.С. Нечипоренко, И.Г. Слысь, А.Б. Медведовский и др. // Порошковая металлургия, 1986. - №1. - С. 96 - 99.

[12] Гаркунов, Д.Н. Триботехника: Учебник для вузов [Текст] / Д.Н. Гаркунов. - М.: Машиностроение, 1989. -328 c.

[13] Степанчук, А.Н. Технология порошковой металлургии: Учебник для вузов [Текст] / А.Н. Степанчук, И.И. Билык, П.А. Бойко. - К.: Вища школа, 1989. $415 \mathrm{c}$.

[14] Бычков, А.С. Концептуальный подход к критериальной оценке возможностей повышения эксплуатационных характеристик деталей авиаконструкций, формуемых методами порошковой металлургии [Текст] / А.С. Бычков // Вопросы проектирования и производства конструкций летательных аппаратов: Сб. науч. тр. Нац. аэрокосмич. ун-та им. Н.Е. Жуковского «ХАИ». - Вып. 4(92). -Х., 2017. - С. 16-25.

[15] Антифрикционные материалы // Химическая энциклопедия. - Т. 1. - М.: Советская энциклопедия, 1988. - С. 184.

[16] Федорченко, И.М. Исследование материалов для тормозных и передаточных устройств [Текст] / И.М. Федорченко, Д.Я. Ровинский, Е.Л. Шведков. К.: Наукова думка, 1976. - 199 с.

[17] Теория выбора и принятия решений [Текст] / Н.М. Макаров, Т.М. Виноградская, А.А. Рубчинский и др. - М.: Наука, 1982. - 326 с.

[18] Эддоус, М. Методы принятия решений [Текст] / М. Эддоус, Р. Стэнсфилд. - Пер. с англ. - М.: Аудит, ЮНИТИ, 1997. - 590 с.

[19] Ларичев, О.И. Качественные методы принятия решений. Вербальный анализ решений [Текст] / О.И. Ларичев, Е.М. Мошкович. - М.: Наука, 1996. 208 c.

[20] Бычков, А.С. Метод последовательного расширения полноты критериальной оценки эффективности использования спеченных порошковых материалов в агрегатах авиаконструкций. Сообщение 1. Спеченные порошковые материалы на основе алюминия [Текст] / А.С. Бычков // Вопросы проектирования и производства конструкций летательных аппаратов: Сб. науч. тр. Нац. аэрокосмич. ун-та им. Н.Е. Жуковского «ХАИ». - Вып. 1(93). -Харьков, 2018. C. $7-18$ 
[21] Зозуля, В.Д. Порошковые триботехнические бронзы, полученные спеканием в режиме СВС [Текст] / В.Д. Зозуля, А.Л. Запара // Порошковая металлургия, 1994. - №1/2. - С. $46-53$.

[22] Триботехнические характеристики порошковых композиционных материалов на основе меди при высокоскоростном трении [Текст] / И.М. Федорченко, Н.Г. Баранов, В.С. Ачеев и др. // Порошковая металлургия, 1986. - №7. - С. 52-56.

Bychkov A. S. ${ }^{1}$, Nechyporenko O. Yu. ${ }^{2}$

${ }^{1}$ State Scientific and Research Expert-Forensic Center of the MIA of Ukraine. Ukraine, Kiev

${ }^{2}$ ANTONOV, State-owned Enterprise. Ukraine, Kiev

\section{CRITERIA OF EFFECTIVENESS OF REPLACING MATERIALS FOR TRIBOTECHNICAL PURPOSES FOR AIRCRAFT FRICTION UNITS Report 1. GENERAL CHARACTERISTICS OF TRIBOTECHICAL MARERIALS. ANTIFRICTION MATERIALS}

The general characteristics of tribotechnical materials are analyzed. The classification scheme of the main types of antifriction materials is synthesized. The block-diagram of the formation of basic operational characteristics of antifriction materials is developed.

Classification components of the operational characteristics are consistent with the relative criteria of the effectiveness of antifriction materials, the numerical definition of which is implemented within the framework of the proposed conceptual approach to the criteria assessment of the possibilities of increasing the operational characteristics of the components of aircraft structures and the method of subsequent expansion of their completeness, predetermined by the formulated objectives of substituting basic antifriction materials. [dx.doi.org/10.29010/082.10]

Keywords: antifriction materials; classification of basic operational characteristic; block-diagram of the formation of properties; criteria of effectiveness for the replacement of materials of friction pairs.

\section{References}

[1] Special technologies and materials of powder metallurgy [Text] / D.S. Kiva, S.A. Bychkov, O.Yu. Nechyporenko, I.G. Lavrenko. - K.: KVITS, 2014. -664 p.

[2] Structural materials in aircraft construction [Text] / A.G. Molar, A.A. Kotsyuba, A.S. Bychkov, O.Yu. Nechyporenko. K.: KVITS, 2015. $-400 \mathrm{p}$.

[3] Powder materials for aviation and rocket-space technology [Text] / A.A. Kotsyuba, A.S. Bychkov, O.Yu. Nechyporenko, I.G. Lavrenko. - K.: KVITS, 2016. - 304 p.

[4] Dictionary-reference of friction, wear and lubrication [Text] / V.L. Zozulya, E.L. Shvedkov, D.Ya. Rovinsky, E.D. Brown. - K.: Naukova Dumka, 1990. - 264 p.

[5] Shvedkov, E.L. Dictionary-reference for powder metallurgy [Text] / E.L. Shvedkov, E.T. Denisenko , I.I. Kovensky. K.: Naukova Dumka, 1982. - 272 p.

[6] Mitin, B.S. Powder metallurgy of amorphous and microcrystalline materials [Text] / B.S. Mitin, V.A. Vasiliev. - M.: Metallurgy, 1992. $-128 \mathrm{p}$.

[7] Fedorchenko, I.M. Modern friction materials [Text] / I.M. Fedorchenko, V.M. Kryachek, V.M. Panaioti. - K.: Naukova Dumka, 1975. - 336 p.

[8] Powder metallurgy and sprayed coating: Textbook for High Schools [Text] / V.N. Antsiferof, G.V. Bobrov, L.K. Druzhinin etc. - Edited by B.S. Mitin. - M.: Metallurgy, 1987. - 792 p.

[9] Tsukerman, V.A. Powder and composite materials [Text] / V.A. Tsukerman. - M.: Nauka, 1976. -128 p. 
[10] Fedorchenko, I.M. Sintered materials for friction units [Text] / I.M. Fedorchenko // Actual problems of powder metallurgy. - Edited by O.V. Roman, V.S. Arunachalma. - M.: Metallurgy, 1990. - P. 12 - 53.

[11] Application of powder bronzes for antifriction materials [Text] / O.S. Nechyporenko, I.G. Slys, A.B. Medvedovsky etc. // Powder metallurgy, 1986. - № 1. - P. $96-99$.

[12] Garkunov, D.N. Tribotechnics: Textbook for High Schools [Text] / D.N. Garkunov. - M.: Mashinostroeniye, 1989. $328 \mathrm{p}$.

[13] Stepanchuk, A.N. Technology of powder metallurgy: Textbook for High Schools [Text] / A.N. Stepanchuk, I.I. Bilyk, P.A. Boyko - K.: Vyshcha shkola, 1989. - 415 p.

[14] Bychkov, A.S. Conceptual approach to the criterial assessment of the possibilities to improve the operational characteristics of aircraft components, using powder metallurgy methods [Text] / A.S. Bychkov // Questions of designing and manufacture of aircraft structure: Coll. sci. tr. of National Aaerospace Un-t named after N.E. Zhukovsky "KhAI". - Issue 4(92) - Kharkov, 2017. - P. 16-25.

[15] Antifriction materials // Chemical Encyclopedia. - T. 1. - M.: Sovetskaya encyclopedia, 1988. - P. 184.

[16] Fedorchenko, I.M. Research of materials for brake and transfer devices [Text] / I.M. Fedorchenko, D.Ya. Rovinsky, E.L. Shvedkov. - K.: Naukova Dumka, 1976. - 199 p.

[17] Theories of choice and decision-making [Text] / N.M. Makarov, T.M. Vinogradskaya, A.A. Rubchinsky etc. - M.: Nauka, 1982. $-326 \mathrm{p}$

[18] Eddous, M. Methods of decision-making [Text] / M. Eddous, R. Stensfild. - Trans. for English - M.: Audit, 1997. $590 \mathrm{p}$.

[19] Larichev, O.I. Qualitative methods of decision-making. Verbal analysis of decisions [Text] / O.I. Larichev, E.M. Moshkovich. - M.: Nauka, 1996. - 208 p.

[20] Bychkov, A.S. Method of consecutive expansion of criterial assessment completeness of efficiency of sintered powder materials use in aircraft structure aggregates. Report 1. Sintered powder materials on aluminum basis [Text] / A.S. Bychkov // Questions of designing and manufacture of aircraft structure: Coll. sci. tr. of National Aaerospace Unt named after N.E. Zhukovsky "KhAI". - Issue 1(93) - Kharkov, 2018. - P. 7-18.

[21] Zozulya, V.D. Powder tribotechnical bronze, received by sintering in SHS-mode [Text] / V.D. Zozulya, A.L. Zapara // Powder metallurgy, 1994. - №1/2. - P. 46 - 53.

[22] Tribotechnical characteristics of powder composite materials on the copper basis for at high-speed friction [Text] / I.M. Fedorchenko, N.G. Rams, V.S. Acheev etc. // Powder metallurgy, 1986. - №7. - P. 52 - 56. 